\title{
Aristotelian vs. Contemporary Perspectives on Relations
}

\author{
JEFFREY E. BROWER
}

Prior to the $20^{\text {th }}$ century, philosophers did not—perhaps even could not—properly appreciate the reality or the irreducibility of relations. Or so many of us have been taught to believe. Indeed, according to a familiar story, full-fledged realism or anti-reductionism about relations did not appear until the late $19^{\text {th }}$ century, when it burst onto the philosophical scene almost wholly unprepared for. As David Armstrong suggests:

Philosophy has been a long time coming to grips with the category of relations .... It is not until the late nineteenth and the twentieth century with C. S. Peirce, William James, and Bertrand Russell that relations begin (no more than begin) to come into focus. (Armstrong 1989, 29)

Echoing these sentiments, with a bit more caution, John Heil writes in his recent entry on relations in the Routledge Companion to Metaphysics:

Indeed, the history of philosophical discussion of relations divides conveniently into the period before and the period after the late nineteenth century. With important exceptions, relations were regarded with suspicion until philosophers working in logic and foundations of mathematics advanced reasons to doubt that we could provide anything like an adequate description of the world without employing a relational vocabulary. (Heil 2009, 312)

According to the familiar story, the late development of our contemporary perspective on relations owes, in large part, to the influence of Aristotle. Sometimes the relevant influence is said to be linguistic or semantic in nature. Undue emphasis on the subject-predicate form of propositions is what prevented the conception of relations as beings or entities corresponding to polyadic predicates. This explanation is at least hinted at in the quotation from Heil, but others make it much more explicit. "Obviously" says Francis Cornford, "the author of the Categories did not conceive of relations as subsisting between two things, as they are now symbolized by $R$ standing between $a$ and $b$ in $a R b$ " (Cornford 1957, 283). 
But sometimes the relevant influence is said to be more metaphysical in nature. Excessive attention to substances and accidents in ontology led to a conception of the world solely in terms of individuals and their monadic properties. As Kenneth Olson suggests:

When Aristotle and the Scholastics talk of relations they mean relational properties. The things related are divided into subject and term, and the relation is held to inhere in the subject, as opposed to holding between subject and term, as Russell has taught us to view it. (Olson 1987, v)

Of course, these linguistic and metaphysical explanations are not incompatible. Bertrand Russell, to whom the familiar story owes much of its popularity, if not its origin, explicitly connects them:

Traditional [i.e., Aristotelian] logic, since it holds that all propositions have the subject-predicate form, is unable to admit the reality of relations: all relations, it maintains, must be reduced to properties of the apparently related terms. (Russell 1914, 56; see also Kneale and Kneale 1962, 31)

In this paper, I aim to show that the familiar story about the development of relations is mistaken in almost every particular. My focus will be on those pre- $20^{\text {th }}$-century philosophers I know best—namely, medieval philosophers living in the Latin West from roughly 400-1400 AD. Although these philosophers were deeply influenced by Aristotle's logic and ontology, I shall argue that, in their case, we can be confident that each of the following is true:

( $\alpha$ Pre-20 $0^{\text {th }}$-century philosophers have a clear understanding of polyadic predicates, and standardly think of relations as beings or entities corresponding to such predicates.

(B) Pre-20 $0^{\text {th }}$-century philosophers have a clear understanding of polyadic properties, and some explicitly identify relations with such properties.

( $\gamma)$ Many, if not most, pre-20 $0^{\text {th }}$-century philosophers accept realism about relations, and many embrace a form of anti-reductionism as well.

If I am right about these claims, the familiar story is obviously in need of serious revision. I

cannot here undertake to provide the necessary revision in all its details, but I will gesture at the form that I think it should take near the end of the paper. My main goal, however, is more modest — namely, to establish that Aristotle's influence, far from being an unfortunate impediment to the proper understanding of the nature and existence of relations, introduced a level of subtlety or sophistication that is sometimes missing from contemporary discussions. 


\section{Relations ANd Polyadic PREDiCAtes}

All theorizing about relations in the Middle Ages begins with Aristotle's short treatise, the Categories. Part of the reason for this is historical. Due to circumstances surrounding the collapse of the Roman Empire, the Categories turns out to be one of the few texts of ancient Greek philosophy available in the Latin West prior to the 1100s, and it is the only text that contains a systematic philosophical treatment of relations. ${ }^{1}$ But part of the reason is also philosophical. Medievals find Aristotle's treatment of relations in the Categories theoretically attractive, and hence are persuaded on philosophical grounds to incorporate its basic framework into their own thinking. ${ }^{2}$

Aristotle's treatment of relations in the Categories has two main components. In chapter 4, he identifies relations (or relatives, as he prefers to call them) with one of the ten categories of being — or more precisely with one of nine distinct categories of accident: "Of things said without any combination, each signifies either substance or quantity or quality or relative ..." (Categories 4, 1b25-26). ${ }^{3}$ Then, in chapter 7 , where he singles out relations for detailed independent consideration, he attempts to identify criteria by which they can be distinguished from the members of all the other categories. In the next section of the paper, I will explore what medievals take to be the implications of Aristotle's identification of relations with accidents.

Here, however, I want to focus on their understanding of the criteria by which he thinks relations can be distinguished.

\footnotetext{
${ }^{1}$ For more details about the availability of Greek texts prior to the 1100 s, see Spade 2013 , esp. $\S 3$ and the references cited therein.

${ }^{2}$ For some discussion of the influence of Aristotle's Categories as a whole on medieval thought, see Pasnau 2012 , esp. §3. For further discussion of the influence of Aristotle’s treatment of relations in particular, see Brower 2010 on which much of the following is based.

${ }^{3}$ All translations of Aristotle are taken, with slight modification, from Barnes 1984.
} 
Aristotle's discussion in Categories 7 is organized around two definitions. The first definition, which the medievals associate with Plato, attempts to characterizes relations in terms of how they are "spoken of": 4

\begin{abstract}
We call the following sorts of things relatives: all those things said to be just what they are of or than something, or toward something in some other way (any other way whatsoever). Thus, what is larger is said to be what it is than another (it is said to be larger than something); and a double is said to be just what it is of another (it is said to be double of something); similarly with all other such cases. (Categories 7 , 6a36-6b.)
\end{abstract}

As the medievals interpret it, this definition distinguishes relations in terms of the predicates by means of which they are signified. Medievals refer to these predicates as relative terms, and understand them, roughly speaking, as terms whose true predication requires a comparison to something other than the subject of which they are predicated. Thus, 'larger' counts as a relative term because when we predicate it of something, we necessarily do so in comparison to something else. We don't assert merely that Simmias is larger; we assert that he is larger than Socrates, or Theaetetus, or the average man. Similar remarks apply to 'double', as well as to all other relative terms. And the point here just appears to be this: a term $F$ is relative just in case a predication of the form ' $F x$ ' is more perspicuously represented as of the form ' $x R y$ '. (If a term is not relative, then the medievals say that it is absolute.) Evidently, therefore, on the first or Platonic definition, relations are identified with the significata of relative terms, where such term are what we would nowadays call polyadic or many-place predicates.

The medievals regard the first or Platonic definition as providing a useful guide to the members of the category of relations. Indeed, they think of it as providing a necessary condition for their identification. Even so, they regard the definition as insufficient, by itself, to distinguish relations from other types of being, and hence they ultimately reject it as too broad. In this

\footnotetext{
${ }^{4}$ Aristotle does not explicitly attribute the first definition to Plato, but his ancient and medieval commentators habitually trace it back to him. This attribution makes its way into the Middle Ages through Boethius and becomes commonplace thereafter.
} 
respect, they take themselves to be following Aristotle himself, who rejects the first definition near the end of Categories 7 on the grounds that it includes certain substances—namely, heads and hands:

If the [first] definition of relatives was adequately assigned, then it is exceedingly difficult, or impossible, to reach the conclusion that no substance is a relative. But if, on the other hand, it was not adequately assigned, and relatives are rather [defined as] those things for which this is their very being: to be toward another in a certain way, then perhaps something may be said about the problem [of heads and hands]. (Categories 7, 8a29-35.)

On the standard medieval interpretation of this passage, Aristotle is noting here that relations cannot be distinguished merely on the basis of linguistic or semantic criteria. For although all relations are signified by relative terms, not all relative terms signify relations. Thus, 'head' and 'hand' are relative terms, as is clear from the fact that predications of the form ' $x$ is a head' and ' $x$ is a hand' are more perspicuously represented as of the form ' $x$ is a head of $y$ ' and ' $x$ is a hand of $y^{\prime}$. Even so, the medievals follow Aristotle in thinking that these terms signify parts of substances rather than relations. On the basis of these and other such examples, therefore, they conclude that relations must be identified not merely with the beings signified by relative terms, but rather with a proper subset of such beings.

Of course, this still leaves us with the question of how genuine relations are to be distinguished from the mere significata of relative terms. Here medieval philosophers think that the second definition, which they take to be Aristotle's own preferred definition, can be of some help. For as they interpret this definition — and in particular the portion italicized in the passage quoted above - it is intended to highlight an important metaphysical role or function that relations play: in addition to being signified by relative terms, relations serve to relate two (or more) things. Or to put the latter point in slightly different terms, relations are that in virtue of which two (or more) things are related. On this interpretation, Aristotle's definition provides a clear explanation for why heads and hands fail to qualify as genuine relations. Although they are 
signified by relative terms, they do not actually serve to relate anything. On the contrary, they are things standing in relations.

This interpretation of Aristotle's preferred definition of relatives, as well as its relation to the first or Platonic definition, turns out to be important for medieval discussions about the precise nature and ontological status of relations. Indeed, it becomes the basis for a common distinction between relations merely according to speech (relationes secundum dici) vs. relations according to being or nature (relationes secundum esse). As Aquinas says in a well-known passage of his Summa Theologiae:

Some relative terms — such as 'master' and 'slave', 'father' and 'son'-are introduced to signify relative dispositions themselves (ipsas habitudines relativas); these terms express things relative secundum esse. But other relative terms - such as 'mover' and 'moved', 'head' and 'headed', and terms of this sort-are introduced to signify things on which certain relations follow; these terms express things relative secundum dici. (Summa Theologiae I, q. 13, a. 7 ad 1)

By now it should be clear that, at least when it comes to distinguishing the members of the category of relations, medievals approach the issue in the same basic way that contemporary philosophers do. Indeed, like us, they have a clear understanding of polyadic predicates, and they rely on them for their understanding of relations. Admittedly, they do not think that relations can be fully characterized in terms of polyadic predicates, but insist instead that they must also be partly characterized in terms of their metaphysical role of relating things. But presumably this is something that contemporary philosophers would agree with as well. If there is a genuine difference in our perspectives on relations, therefore, it must have to do with the precise way in which medievals understand the nature of the beings that do the relating. To see what this understanding is, however, we must return to the other component of Aristotle's treatment of relations in the Categories - namely, his identification of relations with accidents. 


\section{RELATIONS AND POLYADIC PROPERTIES}

So far we have been focusing on just one of the standard explanations of the late development of relations_-namely, a linguistic or semantic one. This explanation, I have argued, is a non-starter. If Aristotle's influence is to blame for the prevalence of reductionism or antirealism about relations, it cannot be because it precludes a proper understanding of polyadic predicates or their importance for distinguishing relations. But there are other, more metaphysical reasons for thinking Aristotle's influence played a role in the late development of relations. His emphasis on substances and accidents in ontology, and in particular his identification of relations with accidents, might also seem to encourage, if not require, some form of reductionism or anti-realism. As Leibniz famously says in a letter to Des Bosses:

You will not, I believe, admit an accident that is in two subjects at the same time. My judgment about relations is that fatherhood in David is one thing, sonship in Solomon another, but the relation common to both is a merely mental thing, whose foundation is the modifications of the individuals. (Look and Rutherford 2007, 326)

Here Leibniz merely echoes things that Aristotle's medieval followers regularly said about accidents. ${ }^{5}$ Indeed, this famous passage provides us with a particularly clear formulation of a standard Aristotelian dictum—namely, that no accident can belong to more than one subject at a time. But if relations are accidents, and no accident can belong to more than one subject at a time, it would seem to follow directly that relations cannot be understood in terms of polyadic properties after all. In which case, the familiar story is right at least to insist that Aristotle's influence on relations did encourage anti-realist or reductionist tendencies.

But here we must be careful. Some philosophers have gone so far as to suggest that the Aristotelian substance-accident ontology prevented those who operated within it from even forming the concept of a polyadic property, and that this explains why they do not share our

\footnotetext{
${ }^{5}$ See Brower 2010, §3.1 for further discussion and references.
} 
perspective on relations. ${ }^{6}$ But this claim is obviously too strong. For Leibniz deploys the very concept being denied to Aristotelians in the passage just quoted ("the relation common to both is a merely mental thing”). Like Leibniz, moreover, medieval Aristotelians habitually speak of relations in polyadic terms, explicitly comparing them to a road that runs between two cities (via), a palisade stretching between two watchtowers (inter-vallum), or a being that somehow stands midway between two extremes (medium). Nor do they take themselves to be original in this regard. On the contrary, they take themselves merely to be following a suggestion of Aristotle's in the Physics, which itself just appears to be part-and-parcel of the common sense conception of relations (see Physics 3, 202b11-15). As the late medieval philosopher Peter Auriol says at one point:

In the third book of his commentary on the Physics, comment twenty, the Commentator [Averroes] says that a relation is a disposition (dispositio) existing between two things (inter duos). But even apart from him it is clear that fatherhood is conceived of as if it were a kind of being standing midway between a father and his son. And the same is true of other relations. (Scriptum super Primum Sententiarum, fols. $318^{\mathrm{v}} \mathrm{a}-\mathrm{b}$; see Henninger 1989, 153-4, n. 12, for the Latin text.)

In light of passages such as these, it is hard to take seriously the suggestion that any

Aristotelians, medieval or otherwise, lacked the concept of a polyadic property. If the medievals were prevented from identifying relations with polyadic properties, therefore, it must have been because their understanding of Aristotelian accidents led them to think there could be nothing in extramental reality corresponding to this concept.

But even this claim turns out to be too strong. For as Heine Hansen (2002) has recently shown, there are some medievals who identify relational accidents with polyadic properties. Hansen focuses on the case of an influential $13^{\text {th }}$-century master, Nicholas of Paris, who uses the very same example that Leibniz does to develop his views. Unlike Leibniz, however, Nicholas insists that fatherhood belongs to two substances at one time:

\footnotetext{
${ }^{6}$ See, e.g., Weinberg 1965, esp. 61-62.
} 
Insofar as 'fatherhood' names a relation, it is not in the father but in the father and the son. (Rationes super Libro Sex Principiorum, f. 14ra; see Hansen 2002, 149 for the Latin text.)

Here we seem to have a clear example of a medieval Aristotelian accepting the existence of polyadic properties. Indeed, it is precisely because Nicholas accepts the existence of such properties that he explicitly denies the Leibnizian view that 'fatherhood' and 'sonship' name distinct properties of the related terms, insisting instead that they are different names for the same relation:

Fatherhood and sonship is one specific type of relation. But it is called by different names according to the different ways of comparing its relata ... For in comparing the father to the son we call it fatherhood, but in comparing the son to the father we call it sonship. (Rationes super Praedicamenta, f. 52va; see Hansen 2002, 151 for the Latin text.)

As Hansen himself emphasizes, what is especially interesting, and surprising, about Nicholas's view is that despite his identification of relations with polyadic properties or accidents, he nonetheless wants to uphold the traditional Aristotelian dictum that accidents do not belong to more than one subject at a time. Thus, in the case of fatherhood and sonship, he insists that the two substances in which this relation inheres count as a single subject:

Fatherhood and sonship is in the father and son as in one subject and not in each of them taken separately ... just as the number four is in four men as in one subject (Rationes super Praedicamenta, f. 54ra; see Hansen 2002, 149-50 for the Latin text.)

It is hard to know exactly what Nicholas has in mind when he speaks of a single accident as being in multiple substances "as in one subject", but the analogy to number is suggestive. Just as the number four can be said to be in several substances "as in a single subject of plural predication," perhaps the same can be said of relations. In any case, what is important about Nicholas's views for our purposes is the following: they demonstrate that, contrary to what the familiar story would have us believe, the Aristotelian identification of relations with accidents, and even the traditional dictum requiring their existence "in a single subject", is compatible with their being polyadic properties. 
Despite the interest and importance of Nicholas's views, most medievals appear to have accepted a more Leibnizian understanding of accidents. It cannot be denied, moreover, that this understanding of accidents did sometimes lead Aristotelian philosophers to embrace a form of anti-realism about relations. Thus, Peter Auriol, immediately after describing relations in the passage quoted above as a sort of "interval" (intervallum), proceeds to deny their existence outside the mind or its apprehension, justifying his conclusion as follows:

It appears that a single thing, which must be imagined as some sort of interval (intervallum) existing between two things, cannot exist in extramental reality, but only in the intellect. [This appears to be the case] not only because nature does not produce such intervals, but also because an intermediate or interval of this sort does not appear to be in either of the two things [it relates] as in a subject, but rather between them where it is clear that there is nothing which can serve as its subject. (Scriptum super Primum Sententiarum, fols. $318^{\mathrm{v}} \mathrm{a}-\mathrm{b}$; see Henninger 1989, 153-4, n. 12, for the Latin text.)

What is interesting about Auriol's argument here is that it takes for granted that relations must be conceived of as polyadic properties. Indeed, like Nicholas before him, Auriol appears to take for granted both of the following two claims:

(1) Relations are that in virtue of which things are related.

(2) That in virtue of which things are related are polyadic properties or accidents.

The first of these two claims expresses the functional understanding of relations associated with Aristotle's definition of relatives. And the second claim is an obvious consequence of combining this functional understanding with the assumption that relations are polyadic properties.

Although both Auriol and Nicholas agree about the truth of (1) and (2), they differ in the implications they draw from them. We can, perhaps, describe this difference in terms of which of two further claims they accept:

(3) There are no polyadic properties or accidents in extramental reality.

(4) Things are related independently of any activity of the mind.

The claim at (3) expresses the Leibnizian understanding of accidents, whereas the claim at (4) expresses what we might think of as common-sense realism. Because Auriol accepts the former, he is driven to reject the latter. By contrast, Nicholas accepts common-sense realism, and hence 
is driven to reject the standard Leibnizian understanding of accidents. Indeed, insofar as (1)-(4)

form an inconsistent set, and both Auriol and Nicholas accept the claims at (1)-(2), they have no choice but reject one of these other claims.

With Auriol, therefore, we do arrive at a genuine form of medieval anti-realism about relations, one that is at least partly motivated by commitment to a broadly Aristotelian substanceaccident ontology. If the familiar story were true, we might expect this sort of anti-realism to be the dominant view among medieval philosophers, given that most of them accept the Leibnizian understanding of accidents that underlies it.

As it turns out, however, this is not the case. Indeed, Auriol's views about relations represent no less of a minority position in the Middle Ages than Nicholas's. And this is because the vast majority of medieval philosophers not only accept the Leibnizian understanding of accidents at (3), but also the common-sense realism at (4). Indeed, as the medievals themselves often point out, denying this aspect of commonsense appears to be tantamount to denying such obvious facts as the real structure of the universe, the mind-independence of composition, causality, spatial proximity, and even the objectivity of mathematical knowledge. As William Ockham says at one point, speaking for the majority of medieval philosophers:

The intellect does nothing to bring it about that the universe is one, or that a whole is composed [of its parts], or that causes in spatial proximity [to their effects actually] cause [their effects], or that a triangle has three [angles], etc. ... any more than [the intellect] brings it about that Socrates is white or that fire is hot or water cold. (Ordinatio I, d. 30, q. 1 in Opera Theologica iv, 316-317. See also Aquinas, De potentia, q. 7, a. 9 and Scotus, Ordinatio II, d. 1, q. 5, n. 224 in Opera Omnia)

It is interesting to note that Auriol worries a great deal about this sort of objection, ultimately suggesting a response that is reminiscent of certain views about secondary qualities. Just as some early moderns insist that, although colors do not exist outside the mind, things can be said to have the powers to produce certain color sensations, so too, Auriol suggests, although relations 
do not exist outside the mind, things do have the powers to produce certain types of comparisons or relational judgments. $^{7}$

Medievals find further support for such common-sense realism in Aristotelian substanceaccident ontology itself. Indeed, such realism was often bolstered by appeal to Aristotle's own insistence that relations constitute one of the nine accidental categories of being. As Aquinas says at one point "Nothing is placed in a category unless it is something existing outside the soul." (De potentia q. 7, a. 9)

For all these reasons, it should be clear that most medieval philosophers reject an assumption common to both Nicholas and Auriol—namely, the assumption that relations just are polyadic properties. That is to say, although they grant the claim that (1) relations are that in virtue of which things are related, they deny the claim that (2) polyadic properties are the beings or entities that do the relating. In short, if we want to contrast the standard medieval position on relations with that of both Nicholas and Auriol, we can do so in terms of a conjunction of the following three claims:

Moderate Realism

(1) Relations are that in virtue of which things are related.

(3) There are no polyadic properties or accidents in extramental reality.

(4) Things are related independently of any activity of the mind.

I refer to this position as moderate realism in order to emphasize that medievals themselves think of it as steering a middle course between radical realism of the sort embraced by Nicholas (which requires the existence of polyadic properties) and radical anti-realism of the sort embraced by Auriol (which requires that nothing can be related independently of the mind). For the sake of completeness, we can also express each of these latter two views in terms of a conjunction of three claims:

\footnotetext{
${ }^{7}$ See Henninger 1989, 169-70 for texts and discussion.
} 
Radical Realism

(1) Relations are that in virtue of which things are related.

(2) That in virtue of which things are related are polyadic properties or accidents.

(4) Things are related independently of any activity of the mind.

Radical Anti-Realism

(1) Relations are that in virtue of which things are related.

(2) That in virtue of which things are related are polyadic properties or accidents.

(3) There are no polyadic properties or accidents in extramental reality.

Like radical realism, the standard medieval position insists that relations exist mindindependently (hence its realism). But like radical anti-realism, it denies that the existence of any polyadic properties outside the mind (hence the moderateness of its realism). We could, if we like, describe the standard medieval position as a form of anti-realism about polyadic properties, since most of its proponents do allow that polyadic properties exist only in the mind. Even so, because this position sharply distinguishes relations from polyadic properties, and insists that relations exist independently of the mind, the position itself clearly qualifies as form of realism about relations.

By now I hope it is clear that most of the elements of the familiar story about relations are mistaken. In the case of medieval Aristotelians, it is simply not true that pre- $20^{\text {th }}$ century philosophers lacked a clear understanding of polyadic predicates or properties, or that such a lack required acceptance of any form of anti-realism or reductionism about relations. On the contrary, almost all medievals thought of relations as corresponding to polyadic predicates, most accepted some form of realism, and at least some explicitly identified relations with polyadic properties. Indeed, those few medievals, such as Auriol, who accepted a form of anti-realism appear to have done so precisely because they identified relations with polyadic properties.

In spite of all this, it might seem that there is still an element of truth to the familiar story. For insofar as the influence of Aristotle encouraged, even if it did not positively require, the standard Leibnizian understanding of accidents at (3), it might still seem to have encouraged 
reductionist tendencies about relations. For if relations are to be identified not with polyadic properties, but rather with properties or accidents that cannot belong to more than one subject at a time, it is hard to see how they could be regarded as in any way irreducible. But even here, I want to suggest, the medievals help us to see that things are more complicated than the familiar story would have us believe.

\section{RELATIONS, REALISM, AND ANTI-REDUCTIONISM}

There were two very different types of moderate realism developed during the Middle Ages. According to the first and more ontologically parsimonious of the two, relations are identified with what we might call ordinary, non-relational accidents - that is to say, with accidents falling under Aristotelian categories other than relation. Peter Abelard is perhaps the best-known representative of this position from the early medieval period. According to him, if Simmias is taller than Socrates, this is to be explained by their respective heights, which are accidents falling under the category of quantity. Again, if Socrates is similar (say, in color) to Plato, this is to be explained by their respective colors, which are accidents falling under the category of quality. And so on for other relations. ${ }^{8}$

According to a second, less parsimonious type of moderate realism, relations are identified not with ordinary, non-relational accidents, but rather with accidents of a sui generis type. John Duns Scotus is perhaps the best-known representative of this position from the later medieval period. According to him, if Simmias is taller than Socrates, this is to be explained by a pair of sui generis monadic properties or accidents that are distinct from, but nonetheless necessitated by, Simmias's and Socrates's heights. Again, if Socrates is similar (in color) to

\footnotetext{
${ }^{8} \mathrm{I}$ am ignoring certain complications here regarding what I have called elsewhere non-paradigmatic relational situations. See Brower 2010 for details, esp. $\$ 5$.
} 
Plato, this is to be explained not by their respective colors, but by a pair of sui generis accidents necessitated by them. And so on for other relations. ${ }^{9}$

In medieval discussions of relations, it is the difference between these two types of moderate realism that constitutes the greatest divide among philosophers. Both parties generally agree that, whenever two (or more) things are related, there must be some non-relational properties or accidents that necessitate the holding of the relation. Such properties or accidents are generally referred to as the "grounds" or "foundations" (fundamenta) of the relation. What the different parties disagree about is whether relations themselves (i.e., the beings or entities that do the work of relating) are to be identified with such foundations. Proponents of the first type of moderate realism say 'yes', and thereby reduce relations to ordinary monadic properties, whereas proponents of the second type say 'no', insisting instead that relations constitute a distinct or irreducible type of monadic property.

Now we might expect anyone inclined both to realism and the rejection of polyadic properties to embrace the reductive type of moderate realism. For as noted above, it is clearly the simplest or most ontologically parsimonious of the two. What is more, failure to reduce relations to ordinary non-relational properties or accidents threatens to make them mysterious. After all, if relations are monadic properties, but not ordinary, non-relational accidents, how are they to be conceived?

Interestingly, it is precisely at this point that Aristotle's influence once again becomes relevant. For like Aristotle, many medievals see a close connection between predication and ontology. Thus, the fact that relations are associated with a distinctive type of predication is often taken as evidence that they have a distinctive type of nature or "quiddity". As one late-medieval philosopher, Henry Harclay, puts the point:

\footnotetext{
${ }^{9}$ Again, ignoring complications associated with non-paradigmatic relational situations.
} 
In the Categories, Aristotle says that the being associated with relatives is being toward another (ad aliud se habere). But it is not the case that the being of a foundation is being toward another. Hence they are not the same. ("Utrum Dei ad creaturam sit relatio realis," n. 43; see Henninger 1987, for the Latin text.) ${ }^{10}$

Indeed, the irreducibility of relations was often thought to be required by Aristotle's insistence that relations constitute a distinct category of being.

Of course, this is not to deny that reductive realists can explain the uniqueness of relative terms and predications without introducing relations over and above their foundations. After all, there mere fact that relative terms are associated with concepts whose content is distinct from that of any non-relational (or absolute) concepts doesn't by itself entail anything about the world. Even so, important questions remain. If Socrates's being similar (in color) to Plato is nothing ontologically over and above Socrates's and Plato's colors, why do we represent it as if it were? In response, it would seem that reductive realists have nothing to appeal to but brute facts about our psychological make-up. We simply do (or at least can) represent one and the same situation in very different ways. As Ockham says in one of his Quodlibetal questions:

Socrates is similar to Plato by the very fact that Socrates is white and Plato is white ... Yet, despite this, the intellect can express these many absolute things by means of concepts in diverse ways: in one way, by means of an absolute concept, as when one says simply 'Socrates is white' or 'Plato is white'; in a second way, by means of a relative concept, as when one says 'Socrates is similar to Plato with respect to whiteness'. (Quodl. VI, q. 25 in Opera Theologica ix, 679.)

Even if one does not find this sort of appeal to psychology implausible, the non-reductive realists would seem to have a much more satisfying reply. For as they see it, the reason that we represent relational situations as distinct from non-relational situation is because they are distinct. Indeed, at this point the non-reductive realists can insist that it is precisely the logical incompleteness of predicates such as 'similar' that calls our attention to what makes these situations distinctnamely, the sui generis nature of the accidents possessed by Socrates and Plato in addition to their respective colors.

\footnotetext{
${ }^{10}$ The translation here is taken, with slight modification, from MacDonald forthcoming.
} 
Now as most medieval non-reductive realists recognize, there is a difficulty posed by their position—namely, that of giving a perspicuous account of the nature of relational accidents. But they often attribute this difficulty to the fact that the nature in question is sui generis. As Albert the Great says, when he turns to the discussion of relations in his commentary on Aristotle's Metaphysics:

It is difficult for us to speak about [the category of] relative or relation because it has a nature and being altogether different from the categories of being that have been considered so far [namely, substance, quantity, and quality]. (Metaphysica, 266a.)

Given that non-reductivists construe the nature of relations as sui generis, it is not surprising that they feel the need to resort to metaphors to describe it. Albert himself appeals most often to a visual metaphor of outward-looking-ness (respectus), and describes individual relations as that in virtue of which their subject "looks out toward another" (respicit ad aliud). Other philosophers, rely on other metaphors and variously describe the nature of relations as a kind of directionality or toward-ness (aditas), as a type of disposition or way of holding oneself (habitudo or relativa habitudo), or again as the source or principle of structure and order (ordinatio). ${ }^{11}$

Of all these metaphors, the ones involving directionality—or intentionality — are likely to be the most helpful to us. For attempts to characterize intentionality in non-relational or "adverbial" terms are not unfamiliar, even if they are no longer as popular as they once were. According to such adverbialism, intentionality is to be understood as a type of property whose intrinsic nature is such that, when it is exemplified by a subject in appropriate circumstances, which include the presence of an appropriate object, it relates the subject to the object in question - in particular, it relates the subject to it as thinker to object thought. This analogy is useful because medieval non-reductive realists typically regard intentionality as a special case (or

\footnotetext{
${ }^{11}$ Harclay uses the term 'toward-ness' (aditas) in his question on relations (see "Utrum Dei," n. 50 in Henninger 1987), whereas Aquinas often uses 'disposition' (habitudo) or 'relative disposition' (relativa habitudo), and eventually comes to prefer 'order' (ordinatio). For a helpful discussion of some of the terms for relations used by medieval philosophers in general, and Aquinas in particular, see Schmidt 1986, esp. 133-40.
} 
special type) of relation. According to them, all relations are to be understood adverbially — that is to say, as properties whose intrinsic nature is such that their exemplification in the appropriate circumstances will relate their subjects to something else. It is just that in certain cases, these properties relate their subjects specifically as thinkers to objects thought.

There is more that could be said about medieval anti-reductionism, and indeed much more would need to be said if we were going to have anything like a full appreciation of it. But I hope that what I have said already is sufficient to show that it would be a mistake to suppose that Aristotle's influence straightforwardly encouraged anti-reductionism about relations.

\section{The FAMILIAR StORY REVISITED}

I have been arguing that the familiar story about relations greatly exaggerates the difference between the Aristotelian and contemporary perspectives on their nature and existence. And we're now in a position to see why. The familiar story runs together a number of different types of claim that can be made about relations, including each of the following:
(a) Relations correspond to polyadic predicates.
(b) Relations are that in virtue of which things are related.
(c) Relations hold mind-independently. ${ }^{12}$
(d) Relations are an irreducible type of being.
(e) Relations are polyadic properties.

The familiar story takes for granted that only an ontology that includes polyadic properties, and hence (e), can uphold either the mind-independence or irreducibility of relations, and hence (c) or (d). And presumably this because the familiar story also takes for granted that polyadic properties are the only type of being that can correspond to polyadic predicates or play the functional role associated with relations (namely, that of relating things), and hence (a) or (b). In short, the familiar story seems to assume that claims (a)-(e) form a tight package.

\footnotetext{
${ }^{12}$ For the sake of co-ordination, I have stated this claim in terms of relations. Strictly speaking, however, it should be understood in terms of what I described earlier as common-sense realism - that is, the claim that things are related independently of any activity of the mind.
} 
But as our discussion of Aristotle's medieval followers makes clear, this assumption is false. These five claims can be pulled apart in various ways, and in any case they must all be kept distinct if we are to have any hope of understanding the actual way in the history of relations developed. For at least from the perspective of medievals, philosophers since Plato have accepted some form of (a), and philosophers since Aristotle have seen the importance of (b). What's more, most medievals accept (c), many accept (d), and some even accept (e). Indeed, those few medievals who reject (c) in favor of some form of anti-realism do so precisely because they accept the identification of relations with polyadic properties at (e).

A clear understanding of the relative independence of claims (a)-(e) turns out to be important for explaining one further type of position in medieval debates about relations that we have not yet fully distinguished - namely, the position of William Ockham. From what we've seen of Ockham's views so far, it might appear that he accepts a form of moderate realismindeed, one according to which relations are identified with ordinary, non-relational accidents (since as he says in a passage quoted earlier "Socrates is similar to Plato by the very fact that Socrates is white and Plato is white"). But this is not quite right. Ockham does allow that things are related independently of the activity of the mind. But he denies that this entails anything about the mind-independence of relations themselves. On the contrary, like Auriol, Ockham accepts the identification of relations with polyadic properties at (e) and takes this to imply the rejection of (c). In order to reconcile these various commitments, Ockham's strategy is to give up something that is taken for granted by almost all medievals before him and indeed seems like a truism—namely, the functional understanding of relations at (b). According to Ockham, relations are not that in virtue of which things are related. On the contrary, things are related in virtue of their extramental foundations - that is, their ordinary, non-relational accidents. By contrast, 
relations are beings existing only in the mind. We might formulate this position as follows: even though a statement like 'Similarity exists' cannot be true independently of the mind, a statement like 'Socrates is similar to Plato' can be. This formulation helps to explain what Ockham means when he expresses his position using such otherwise unintelligible formulae as: "This white thing really is similar [to that one], even though similarity is not really in this white thing" (Quodl. VI, q. 22 in Opera Theologica ix, 669). It also helps to explain how Ockham's position complicates the standard medieval debate about whether relations are identical to their foundations. Ockham thinks the correct answer to this question is 'no', for nothing in the mind can be identical to anything in extramental reality. But unlike almost everyone else who gives this same answer, Ockham does not thereby commit himself to the view that relations constitute a distinct or irreducible type of being, and hence can consistently reject the claim at (d).

Insofar as Ockham's position denies the existence of relations outside the mind, it must be characterized as a form of anti-realism about relations. But insofar as it also upholds the common-sense view that things can be related mind-independently, it is a much more moderate form of anti-realism than that of Peter Auriol. Indeed, as Ockham's position helps us to see, there are really two different types of anti-realism, as well as two different types of realism, to be distinguished in medieval debates about relations, depending on where proponents stand with respect to claims (a)-(e). For the sake of clarity, we can set out these four types of position as indicated in the table below:

\begin{tabular}{|l|c|c|c|c|}
\hline & $\begin{array}{c}\text { Radical Realism } \\
\text { (e.g., Nicholas) }\end{array}$ & $\begin{array}{c}\text { Moderate Realism } \\
\text { (e.g., Abelard/Scotus) }\end{array}$ & $\begin{array}{c}\text { Radical Anti-Realism } \\
\text { (e.g., Auriol) }\end{array}$ & $\begin{array}{c}\text { Moderate Anti-Realism } \\
\text { (e.g., Ockham) }\end{array}$ \\
\hline $\begin{array}{l}\text { (a) Relations } \\
\text { correspond to polyadic } \\
\text { predicates. }\end{array}$ & + & + & + & + \\
\hline $\begin{array}{l}\text { (b) Relations are that } \\
\text { in virtue of which } \\
\text { things are related. }\end{array}$ & + & + & + & - \\
\hline $\begin{array}{l}\text { (c) Relations hold } \\
\text { mind-independently. }\end{array}$ & + & + & - & + \\
\hline
\end{tabular}




\begin{tabular}{|l|c|c|c|c|}
\hline $\begin{array}{l}\text { (d) Relations are an } \\
\text { irreducible type of } \\
\text { being }\end{array}$ & + & $+/-$ & - & - \\
\hline $\begin{array}{l}\text { (e) Relations are } \\
\text { polyadic properties }\end{array}$ & + & - & + & + \\
\hline
\end{tabular}

As will perhaps be obvious, I use a plus sign (+) to indicate acceptance of a given claim and a minus sign (-) to indicates its rejection. In the case of moderate realism, moreover, I have used a combination of both signs (+/-) to indicate its compatibility with either the acceptance or rejection of $(\mathrm{d})$, which is what gives to the distinction between its reductive and anti-reductive forms. $^{13}$

To tell a complete story about the development of relations prior to the $20^{\text {th }}$ century, one would have to say something about the main lines of influence on the acceptance or rejection of the claims constitutive of these four positions. We have already seen some of these. Perhaps with the exception of claim (c), which appears to be part of commonsense, Aristotle's discussion of relatives is at least partly responsible for introducing all the other claims into the discussion. Indeed, his own preferred definition of relatives, and its intuitiveness on the standard medieval interpretation, ensured that almost everyone accepted (a) and (b). And this, together with the common-sense claim at (c), created some pressure to accept at least (d), if not also (e). And, indeed, (e) seems to have struck some medievals as so plausible in itself (perhaps because of the connection between relations and polyadic predicates?) that they were prepared to go to fairly radical extremes to uphold it — including either giving up the standard Leibnizian conception of accidents (according to which there are no polyadic properties in extramental reality), or embracing a radical form of anti-realism (according to which things are not related

\footnotetext{
${ }^{13}$ There is a sense in which even the anti-reductive form of moderate realism might be regarded as fairly radical, so perhaps the moderateness of moderate realism should be thought of as coming in degrees.
} 
independently of the mind), or even denying an apparent truism about the functional nature of relations (according to which relations are things that relate).

Still, none of this really addresses what is perhaps the chief question that remains. What is it that led most medievals to reject the existence of polyadic properties outside the mind? Suppose the familiar story is wrong to trace such a rejection to some sort of confusion, or even to suggest that it is somehow entailed by the traditional conception of Aristotelian accidents. How else is it to be explained? And why would such a view be so widespread, shared by almost all medievals except the few who embraced radical realism?

This is a big question, and one that I cannot attempt fully to answer here. But the short answer, I think, has to do with general ontological considerations. And perhaps the most important one here is that medievals are, by and large, committed to some form of trope nominalism. ${ }^{14}$ But just as most trope theorists nowadays are loath to admit anything other than monadic tropes, so too in the case of medievals. ${ }^{15}$

There are, of course, other questions that would have to be answered before anything like a complete history of relations could be given. For example, if I am right to think that medieval Aristotelians, and perhaps Aristotelians in general, had a clear understanding of relational predication, one might wonder why it took so long for this understanding to be incorporated into a formal logic of relations. Again, medievals are not the only pre-20 $0^{\text {th }}$-century philosophers, or for that matter, the only such philosophers to have been influenced by Aristotle. How do the discussions of relations in other pre- $20^{\text {th }}$-century philosophers compare with them?

\footnotetext{
${ }^{14}$ This is actually suggested by Leibniz's own statement about accidents. For if there were universal accidents, then even ordinary, non-relational accidents could belong to more than one subject at a time.

${ }^{15}$ No doubt, medieval resistance to polyadic properties is also bound up with their commitment to a broadly Aristotelian form of hylomorphism, and in particular the view that substances and accidents combine to generate compounds of both. See Brower forthcoming, $\$ 9.3$ for discussion of this ground of resistance in the specific case of Aquinas.
} 
These sorts of questions fall outside the scope of my investigation here. But on the basis of what we have seen here, we can, I think, reasonably expect that, whatever their answers are, they are likely to be much more subtle or sophisticated than the familiar story would have us believe. $^{16}$

\footnotetext{
${ }^{16}$ Earlier versions of this chapter were presented at the 2012 Metaphysics of Relations conference in London, and at the 2013 Ontology of Relations conference in Lausanne. I am grateful to members of the audiences on these occasions for helpful comments and discussion. I am also grateful to Michael Bergmann, Susan Brower-Toland, and Jonathan Jacobs for detailed comments on an earlier draft.
} 


\section{REFERENCES \\ (Medieval authors are listed by first name)}

Albert the Great. 1960-64. Metaphysica. In Alberti Magni Opera omnia edenda curavit, vol. 16, ed. Bernhard Geyer. Münster: Aschendorff.

Armstrong, David. 1989. Universals: An Opinionated Introduction. Boulder, CO: Westview Press.

Barnes, Jonathan, ed. 1984. The Complete Works of Aristotle. Princeton: Princeton University Press.

Brower, Jeffrey E. Forthcoming. Aquinas's Ontology of the Material World. Oxford: Oxford University Press. . 2010. "Medieval Theories of Relations," The Stanford Encyclopedia of Philosophy (Winter 2010 Edition), Edward N. Zalta (ed.), URL = $<$ http://plato.stanford.edu/archives/win2010/entries/relations-medieval/>.

Cornford, Francis. 1957. Plato's Theory of Knowledge: The Theaetetus and the Sophist. New York: McMillan Publishing Company.

Hansen, Heine. 2012. "Strange Finds, or Nicholas of Paris on Relations." In Logic and Language in the Middle Ages: A Volume in Honour of Sten Ebbesen, eds. Jakob Leth Fink, Heine Hansen, and Ana María Mora-Márquez, 139-154. Leiden: Brill.

Heil, John. 2009. "Relations." In The Routledge Companion to Metaphysics, eds. Robin Le Poidevin, Peter Simons, Andrew McGonigal, and Ross Cameron, pp. 310-321. London: Routledge.

Henninger, Mark G. 1989. Relations: Medieval Theories 1250-1325. Oxford: Clarendon Press. . 1987. "Henry of Harclay's Question on Relations," Mediaeval Studies 49: 76-123.

John Duns Scotus. 1950-. Ioannis Duns Scoti Ordinis Fratrum Minorum Opera Omnia, eds. Carol Balić et al. Vatican City: Vatican Polyglot Press.

Kneale, William and Martha Kneale. 1962. The Development of Logic. Oxford: Oxford University Press.

Look, Brandon and Donald Rutherford, eds. 2007. The Leibniz-Des Bosses Correspondence, ed. Look and Rutherford. New Haven: Yale University Press.

MacDonald, Scott, ed. and trs. Forthcoming. Cambridge Translations of Medieval Philosophical Texts: Metaphysics. Cambridge: Cambridge University Press. 
Olson, Kenneth. R. 1987. An Essay on Facts. Chicago: Chicago University Press.

Pasnau, Robert. 2012. "Latin Aristotle.” In The Oxford Handbook of Aristotle, ed. Christopher Shields, 665-89. Oxford: Oxford University Press, 2012.

Russell, Bertrand. 1914. Our Knowledge of the External World: As a Field for Scientific Method in Philosophy. Chicago: Open Court.

Schmidt, Robert W. 1986. The Domain of Logic According to Saint Thomas Aquinas. Hague: Martinus Nijhoff.

Spade, Paul Vincent. 2013. "Medieval Philosophy," The Stanford Encyclopedia of Philosophy (Spring 2013 Edition), Edward N. Zalta (ed.), URL = http://plato.stanford.edu/archives/spr2013/entries/medieval-philosophy/

Thomas Aquinas. 1888-1906. Summa Theologiae. In S. Thomae Aquinatis Doctoris Angelici Opera Omnia, vols. 4-12. Rome: Leonine Commission. 1965. Quaestiones disputatae de potentia, ed. P. M. Pession. Rome: Marietti.

Weinberg, Julius. 1965. Abstraction, Relation, and Induction: Three Essays in the History of Thought. Madison, WI: University of Wisconsin Press.

William Ockham. 1974-88. Opera Theologica, eds. Gedeon Gal et al. St. Bonaventure, NY: The Franciscan Institute. 